\title{
Monitoring Construction Equipment for Automated Project Performance Control
}

\author{
by \\ Rafael Sacks ${ }^{1,2}$, Ronie Navon ${ }^{2}$, Aviad Shapira ${ }^{2}$ and Irina Brodetsky ${ }^{2}$
}

\begin{abstract}
The ability of company managers to respond to variations in performance in construction projects is severely limited by the time delay common in existing information and control systems in reporting schedule, budget and quality deviations from plan. We propose a system for interpreting data acquired automatically by monitoring the activity of major construction site equipment, such as tower cranes, concrete pumps, etc. The primary objective is to provide a reliable, real-time, automatic source of project performance information for construction managers. This requires interpretation of the monitoring results using a knowledge-based rule processor, and relies on the existence of a computerized Building Project Model.
\end{abstract}

KEYWORDS: Automation; Construction equipment; Information technology; Monitoring; Project performance control.

\section{INTRODUCTION}

The impact of management decisions on the work carried out on a construction site is severely limited by the time delay required in order to provide accurate reports of project performance in terms of schedule, budget and quality. In existing information and control systems, status reports are commonly delivered with very long time lags, resulting in undesirable trends being identified too late for corrective measures to be taken. Consequently, fully automatic monitoring of indirect performance parameters, and processing of the data to provide informative indicators of project progress, have been proposed (Navon and Goldschmidt 2001). Progress indicators can be compared to project control limits to deduce the project performance and identify problems. If the project information is directly available in the form of a computerized building project model, the interpretation can be done using knowledge-based software.

A focused research effort is currently under way at the Technion (Israel Institute of Technology) to develop the principles for:

-1 fully automated data collection on construction sites (Navon and Goldschmidt 2002),

-2 knowledge-based interpretation of the data in relation to a computerized Building Project Model (BPM) (Sacks 1998).

-3 provision of useful information about the schedule, cost and quality of the work being performed.
The generic term for systems using this approach is "Automated Project Performance Control" (APPC). The aim of such systems is to support the overall APPC goal of shortening the reporting cycle to one day, while eliminating the effort of reporting entirely. A number of projects have been initiated as part of this effort: a labor monitoring system using Automated Data Collection technology (Navon and Goldschmidt 2001, Navon and Goldschmidt 2002, Sacks et al. 2002), a system for monitoring and reporting work performed by heavy earthwork equipment (Navon, Goldschmidt and Shpatnitzky 2002), and a material control system.

Nearly all of the materials and components for a building are lifted into place by construction equipment, such as tower and mobile cranes, concrete pumps, hoists, etc. Tracking and recording the activity of such equipment is technologically straightforward. For these reasons, the authors propose that monitoring construction equipment holds the potential to provide significant data for APPC.

The system solution is a typical monitor and control loop (see Figure 1). The main part the control system is a decision rules processor. The processor receives data daily from the monitoring 'black box' installed on the equipment. This input consists of load weights and crane-hook location coordinates gathered from the equipment through its working day. The location measurements are translated into the local site coordinate system so that they can be related to particular building elements 
or activities. The rules processor draws on a knowledge base of typical historical data, such as unloading durations or profiles for different construction activities, typical weights and heights of auxiliary equipment (between the hook and the load), spatial volumes typical of construction activities, etc. The data describing the project itself are drawn from a Building Project Model based interface, including details of pending activities (start/finish dates, duration, main material components and their approximate weights), probable storage areas and material delivery zones, etc.

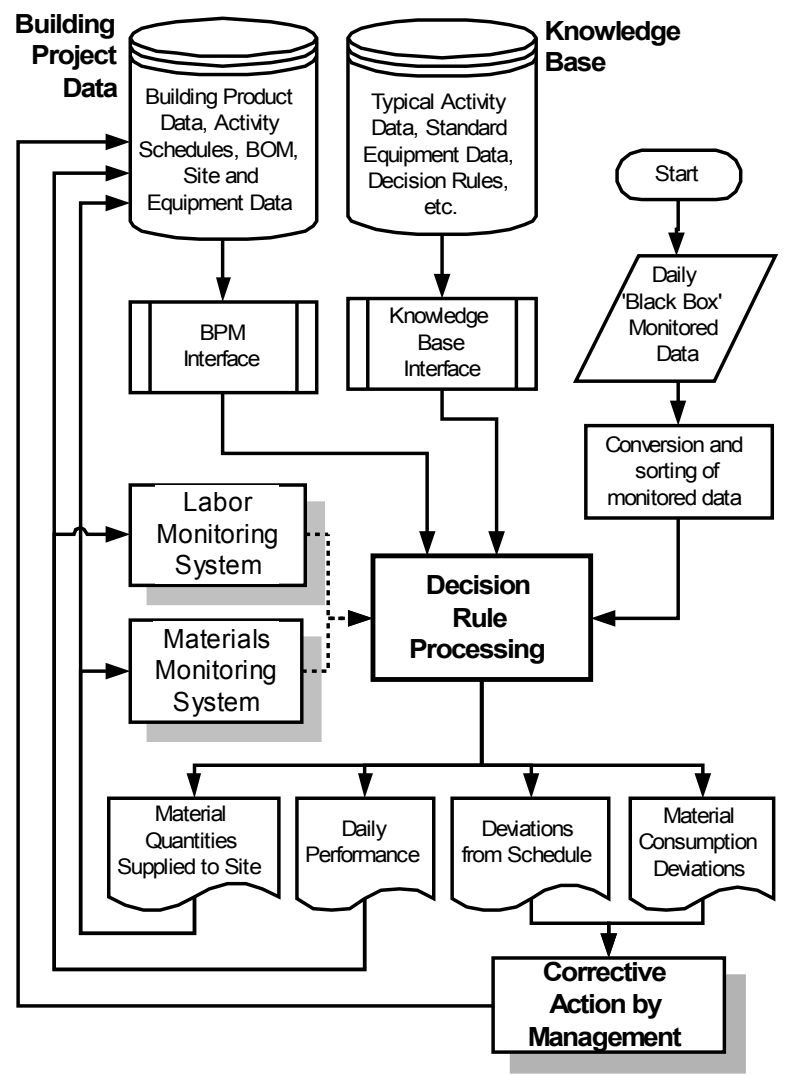

Figure 1. Construction Equipment Monitoring System

Using these three sources, the system is required to correlate the equipment movements with particular activities. It can then draw conclusions, with some calculated level of certainty, about the performance of any particular activity, and can provide additional information for other existing control systems (such as Materials and Labor Control Systems). Finally, the information provided is made available to management, and is used to update the project database.
In the following sections, the technology for monitoring equipment is presented for the typical case of construction tower cranes. Next, we detail the system information flow and the logic required for interpreting the data collected, and outline the implications for detailing of the necessary Building Product Model objects and relationships. Finally, we discuss the potential modes of use and benefits of equipment monitoring APPC systems.

\section{AUTOMATED MONITORING OF CONSTRUCTION EQUIPMENT}

The particular case of tower cranes is used here as an example (the methodology and technologies for other equipment types are similar). Selection of the monitoring equipment is dependent on the data required. These are identified as:

$$
\begin{aligned}
& W_{g}(t) \text { - the gross weight of the load being } \\
& \text { lifted measured continuously through } \\
& \text { time. } \\
& L_{h}(t) \text { - } \begin{array}{l}
\text { the location of the hook in local } \\
\text { building coordinates measured } \\
\text { continuously over time. }
\end{array}
\end{aligned}
$$
$L_{h}(t)$ - the location of the hook in local building coordinates measured continuously over time.

Typical plots of $W_{g}(t)$ and $z_{h}(t)$ - the height coordinate of $L_{h}(t)$ - are shown in Figure 2. At least two distinct technological possibilities exist for measuring these:

a) Separate Load and Location Measurement. A variety of tensile links, crane-scales, load measuring pins, load cells and others are available for measuring the gross load weight with maxima ranging from $500 \mathrm{~kg}$ to 100 tons (MSL 2002, Strainstall 2002). Most have cable or telemetry connections to a central interface block. Their accuracy is typically about $\pm 1 \%$ of actual readout. A data recorder must be added. For location monitoring, a Global Positioning System (GPS) receiver may be used (Roberts et al. 1999). A pair of receivers may be used and operate in differential mode to avoid transmission interference, and to achieve sub-metric accuracy (Peyret et al. 2000). GPS coordinates can be translated into local coordinates (Navon and Goldschmidt, 2002). 


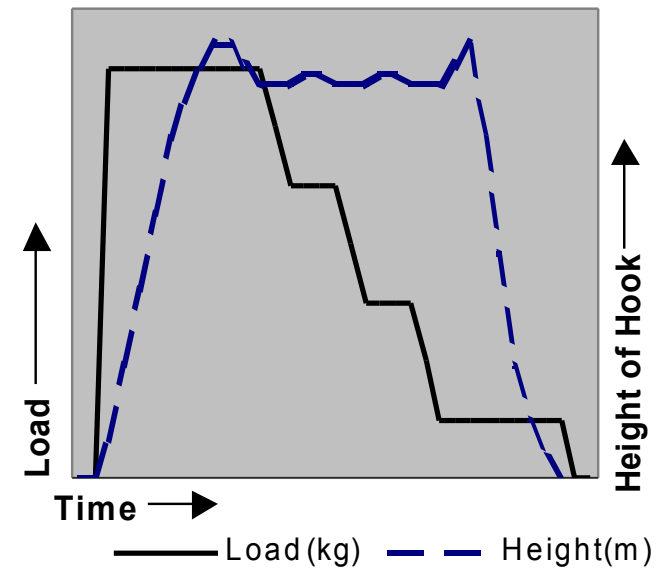

Figure 2. Typical Concrete Bucket Loading and Unloading Profile for Pouring a Slab.

b) Built-in monitors supplied by the equipment manufacturer. Large construction plant companies offer optional crane monitoring systems that provide real time monitoring of weight and location parameters. For example, Potain's 'Dialog Visu' control system enables real-time monitoring and recording of the 'onhook weight', and of the hook position in terms of boom rotation angle, radius of the trolley from the tower, and height of the hook from the ground (Potain 2002). (This definition of location, about the tower axis, can be considered a 'local crane polar coordinate system'). It should be noted that these advanced control systems are intended mainly to enhance site-safety, for more accurate crane operation in zones with reduced visibility, and for operation with remote control. They can be programmed to give warning against overload or to prevent travel into dangerous zones. They were not intended for project performance control purposes.

\section{INTERPRETING MONITORED DATA}

Comparing these data with calibrated typical load data and with the project model information should allow the system to draw conclusions about the type and identity of the building element being worked on the material or equipment being lifted, to identify supply of material to the site, and to identify the specific construction activity being performed.

\subsection{Knowledge Based Rules}

The knowledge rules encompass all of the processing as laid out in. It is envisaged that most of these will use production rule format expressions of the logic, although other techniques may be employed as needed. For example, consider derivation of the identity of the load, which is a central piece of information. Not only can the load itself be compared with known loads, but the pattern of unloading over time may also be matched with a library of typical patterns, such as the pattern for unloading concrete from a bucket for pouring a slab, as shown in Figure 2. In the figure the multiple points of unloading, and the residual load of the bucket during descent, are typical of casting concrete using a bucket on a crane. Recording a library of such patterns, and deriving pattern-matching rules from them, is therefore one of the tasks required for development of the knowledge base.

\subsection{Project Data Model Information Requirements}

Processing the knowledge-based rules outlined above requires that up-to-date information describing the construction project be available in computerized form. Given the diversity of sources of this information, we assume that it will be provided by means of a Building Product Model (Eastman 1999). The information must cover three main areas:

-1 the building product: the physical parts of the building.

-2 the construction process: the activities through which the building is built.

-3 the resources employed in construction (materials, equipment and labor).

The details of these are illustrated in the following discussion using the example of construction of a simple reinforced concrete column.

First, the existence of the column, in a particular geometric location in terms of the building's local coordinate system, and having a specific shape, must be known, so that the location of delivery of equipment and materials 


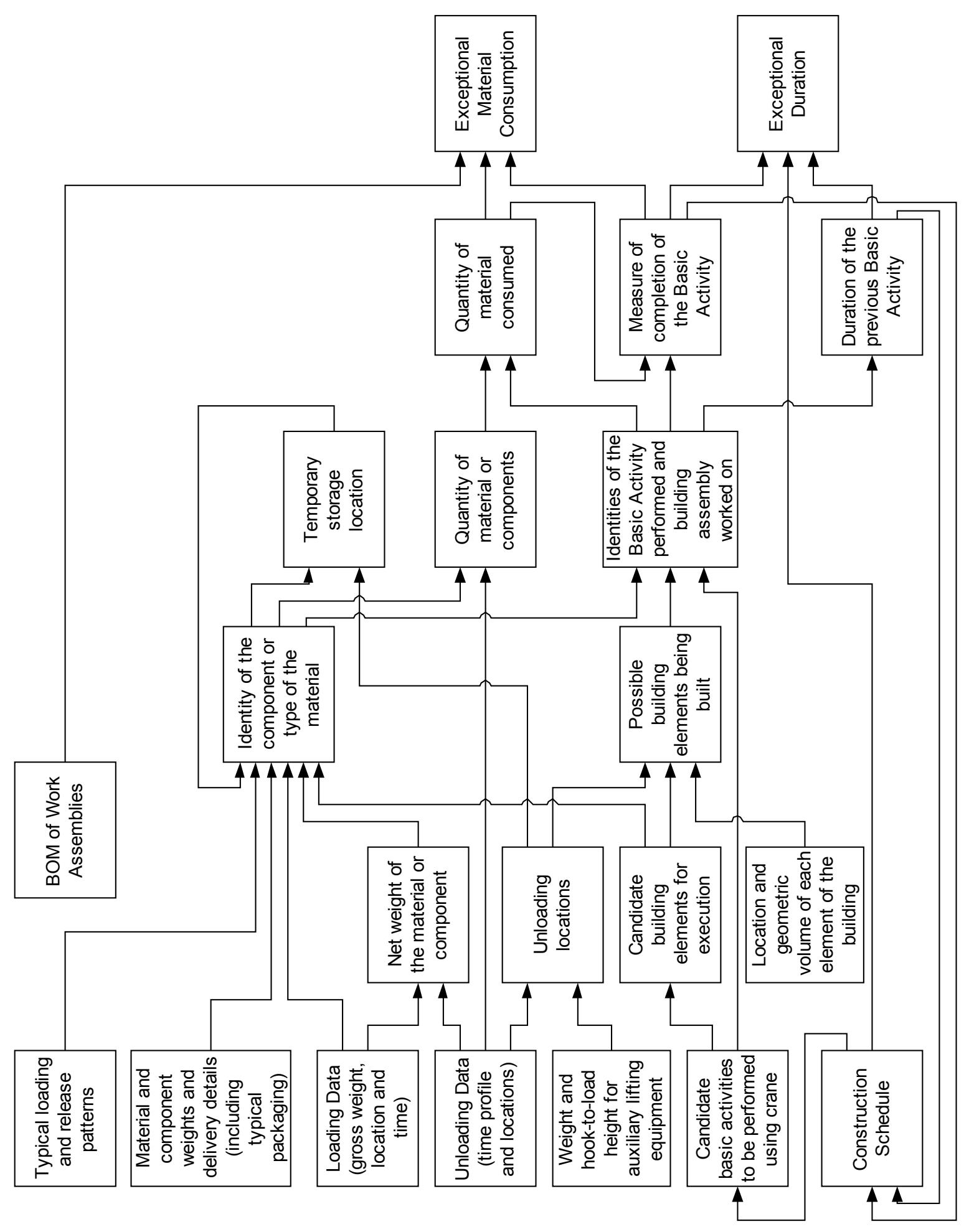

Figure 3. Rule processing flow. 
can be correlated with a specific building element. The physical components of the column - the reinforcing cage and the concrete - must also be identified and described in sufficient detail to allow calculation of their weight and location. The fact that the column is part of an assembly consisting of the other RC columns on the building's floor (and possibly also the slab it supports) must also be known. These basic aspects of building product information - product identity, location, geometric shape, material type and assembly/component aggregation - are included in Building Product Models such as the IFC 2.x schema (IAI 2001). They are communicated in the CIS/2 structural steel product model (CIS/2 2001).

Second, the nature of the construction method and the planned schedule of construction activities must be available. At the simplest level, knowing whether the column is precast or cast-in-place is critical to interpreting the lifting data. Each construction activity, such as 'build $4^{\text {th }}$ floor columns' must be fully defined in terms of its scope (the elements it includes - which columns are to be built), its scheduled start time and duration, the activities which precede or succeed it, and the resources that will be used and/or consumed in its execution (see next paragraph). However, this level of detail is insufficient to allow conclusions to be drawn using the rules outlined above. The basic activities of each activity (as defined by its construction method - Sacks and Warszawski 1997), must also be detailed (Sacks et al. 2001). For an assembly of cast-in-place RC columns, the activity 'Build Columns' would include the following basic activities: prepare column forms, fix rebar cages in place, position and stabilize forms, pour concrete, compact concrete and strip the forms. It is at this level that the APPC system contemplated here can identify execution of an activity - by associating the specific loads and unloading patterns of equipment and materials with specific sequences of basic activities. Some of these aspects of the construction process are provided in computerized construction schedules (note that the problem of updating schedules is specifically addressed by APPC. Nevertheless, while construction managers will be relieved of the need to input historic data, they will still be required to update their future intent).

Third, the resources of interest are those lifted by the crane - equipment (such as steel forms for RC columns) and materials (rebar cages and buckets of concrete). Their identity, function (i.e. association with a basic activity type), and weight must be detailed. In all cases except for bulk materials, their shape and center of gravity are required. Some resources, such as precast concrete pieces (elements), rebar cages, etc are project specific, while others, such as steel shutters, concrete buckets, etc. and all bulk materials, are generic across many projects.

Note that certain prefabricated parts of a building are defined as 'products'. For the proposed system to function, the fact that they also exist as material 'resources' (prior to their erection in the building) must be stored explicitly.

\section{POTENTIAL BENEFITS}

The processed information will be used for progress monitoring to produce 'as-made' information for updating project schedules. Additionally, it will be used as input to existing models - e.g. labor inputs control (Navon and Goldschmidt 2002) - for crossreference purposes, thus improving their decision-making algorithms. Additionally, the research is expected to explore the potential for generating significant additional information from monitoring lifting equipment, such as:

-4 Accurate quantities (weights) of materials supplied (e.g. precise quantity of concrete poured), steel installed, etc.

-5 Patterns of building structure weights and their distributions (for long term validation of structural design codes).

-6 Potentially life-saving real-time information of crane hook location vis-avis worker locations (monitored with hardhat GPS - Navon and Goldschmidt 2001).

-7 The identity and quantity of materials delivered to the site and the movement of materials within the site, for materials control purposes.

-8 Data regarding the availability of equipment and materials necessary for scheduled activities prior to their 
commencement, to avoid delays and reduce downtime for crews.

-9 Data that can be used for improving the efficiency of equipment operating procedures, and/or of other aspects of the production process (e.g. work study data).

\section{CONCLUSIONS}

The concept of automated monitoring of construction equipment, within the framework of an Automated Project Performance Control system, holds the potential to greatly enhance the ability of construction managers to respond quickly to project performance problems. A road map for both the measurement and information technologies that are required has been set out. Ongoing research will focus principally on developing and testing the knowledge-base that must interpret raw monitoring data and produce reliable performance information.

\section{REFERENCES}

Ciesielski, C. A., (2000). "ADCIC - Automatic Data Collection in Construction." A.I.M.'S Global Academic \& Scientific Conference. Cairo (Egypt).

CIS/2 - CIMsteel Integration Standards 2, (2001). http://www.cis2.org

Eastman, C.M., (1999). "Building product models: computer environments supporting design and construction," CRC Press, Boca Raton, Florida.

IAI (2001). International Alliance for Interoperability (http://www.iai.org), Industry Foundation Classes IFC Release 2.0.

Monitoring Services (UK) Ltd. (2002). "Load Transducers \& Telemetry Monitoring Systems", www.msl.ision.co.uk

Navon, R., and Goldschmidt, E., (2002). "Automated Data Collection for Labor Inputs Control," Automation in Construction (accepted).
Navon, R., and Goldschmidt, E., (2002). "Can Labor Inputs be Measured and Controlled Automatically?" ASCE Journal of Construction Engineering and Management (accepted).

Navon, R., Goldschmidt, E., and Shpatnitzky, Y., (2002). "Field Test of an Automated Location Measurement for Project Performance Control," Special issue on Automated Data Capture Technologies of the Journal of Computer-Aided Civil and Infrastructure Engineering (accepted).

Peyret, F., Betaille, D., and Hintzy, G., (2000). "High-Precision Application of GPS in the Field of Real-Time Equipment Positioning. Automation in Construction, 9: 299-314.

Potain S.A. Ltd. (2002). "Lifting Equipment Products", www.potain.com

Roberts, G. W., Dodson, A. H., and Ashkenazi, V., (1999). "Global Positioning System Aided Autonomous Construction Plant Control and Guidance". Automation in Construction, 8: 589-595.

Sacks, R., (1998). "Issues in the Development and Implementation of a Project Model for an Automated Building System," International Journal of Construction Information Technology, Salford University, Salford UK Vol. 5 No 2 pp. 75-101.

Sacks R., Navon, R., and Goldschmidt, E., (2001). 'Building Project Model Support for Generating Automated Project Performance Control Information', submitted to the ASCE Journal of Computing in Civil Engineering, December 2001.

Sacks, R., and Warszawski, A., (1997). "A Project Model for an Automated Building System: Design and Planning Phases," Automation in Construction, Elsevier Science Publishers B.V., Vol. 7 December 1997 pp. 2134.

Strainstall (UK) Ltd. (2002). "Industrial Load Measurement", www.strainstall.com 